\title{
Brain Disorders and Novel Therapeutics
}

\author{
Hanns Möhler*
}

\begin{abstract}
Using the power of genetic intervention, a strategy is illustrated which permits new insights into the pathobiology of brain diseases and the discovery of new therapeutic strategies. Brain function is based on a delicate balance between excitory and inhibitory neurotransmission. Selective circuits of GABAergic inhibitory transmission were targeted by introducing point mutations in defined $\mathrm{GABA}_{\mathrm{A}}$ receptor subtype genes in mice (knock-in strategy). New behavioural phenotypes were generated which reflect various brain disorders. In addition, novel drug targets were identified for the treatment of anxiety disorders, sleep disturbances, memory deficits, and schizophrenia.
\end{abstract}

Keywords: Anxiety · Diazepam $\cdot$ GABA $\cdot$ GABA $_{A}$ receptor subtypes · Memory

\section{Phenotypes through Pharmacology}

Pharmacology is the bridge between biology and medicine. This bridge has to be strengthened to improve human health. The architecture of the bridge is fascinating since it contains all levels of biological organisation from genes to behaviour, making pharmacology one of the most interdisciplinary sciences in the field of medical biology and therapeutics. By unravelling the pathobiology of disease and by developing new therapeutic strategies, pharmacology provides the phenotypes for new pharmaceuticals. This approach is illustrated here with a description of new phenotypes for the treatment of brain disorders.

\section{Probing Brain Functions by Drugs and Mutations}

Mental and cognitive disorders reflect abnormalities in the interaction between the brain and the environment. In order to identify the neuronal abnormalities which underlie such disorders, it is our strategy to probe brain functions by genetic means and by drugs (Fig. 1). The resulting behavioural phenotyps permit the identification of molecular targets for therapeutic intervention.

In the harmonious brain, excitatory and inhibitory neurotransmission exist in a purposeful balance. Neurons operating with the neurotransmitter GABA provide the most prominent inhibitory signal throughout the brain. Ubiquitous inhibitory feed forward and feed back circuits keep excita- tion under control. GABA exerts its actions via $\mathrm{GABA}_{\mathrm{A}}$-receptors, which are GABAgated chloride channels. These receptors are prominent drug targets. Benzodiazepines exert their therapeutic actions as hypnotics, anxiolytics and anticonvulsants by enhancing GABAergic transmission [1-3]. Since benzodiazepines interact with nearly all $\mathrm{GABA}_{\mathrm{A}}$ receptors in the brain their utility is limited by non-selectivity and by side effects.

Clearly, a future drug therapy of brain disorders would benefit from targeting selective GABA circuits for specific therapeutic indications. This vision became real-

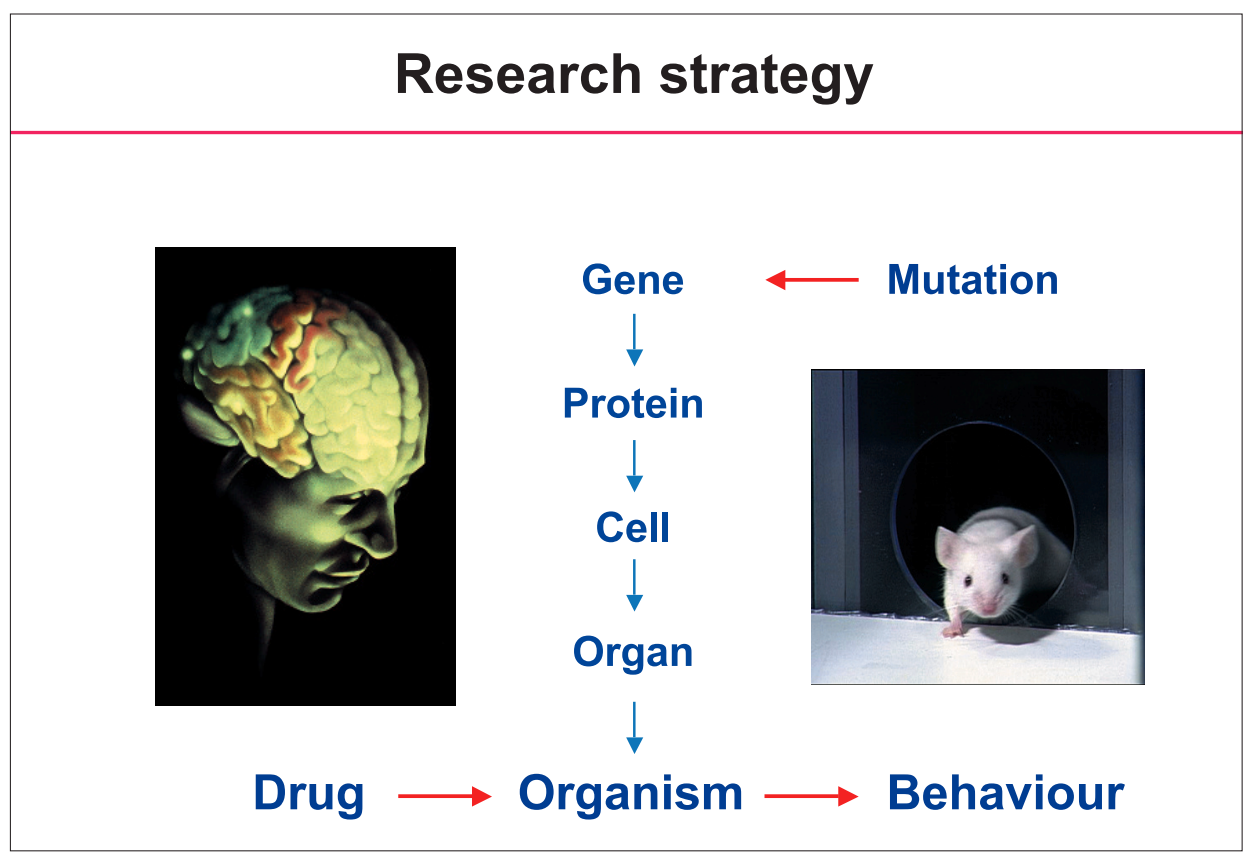

${ }^{*}$ Correspondence: Prof. H. Möhler Institute of Pharmacology University of Zurich and

Department of Chemistry and Applied Biosciences Institute of Pharmaceutical Sciences

Swiss Federal Institute of Technology

Winterthurerstrasse 190

$\mathrm{CH}-8057$ Zürich

Tel.: +4116355910

Fax: +411635 5708

E-Mail: mohler@pharma.unizh.ch

http://www.unizh.ch/Phar/

Fig. 1. Behavioural phenotypes serve as models of human disease and point the way to new therapeutic strategies. Genetic means and drug interactions are used to identify new behavioural phenotypes relevant for unmet medical needs. 
ity due to major achievements of our research group which are described in the following. 1) GABA $\mathrm{A}_{\mathrm{A}}$ receptor subtypes were identified and found to be expressed in distinct GABA circuits (Fig. 2). GABA Ge- $^{-}$ ceptor subtypes therefore serve as selective targets for future drugs which tag distinct GABAergic circuits [4-7]. 2) The pharmacological functions of distinct GABA circuits were identified by genetic means. A point mutation was introduced into distinct $\mathrm{GABA}_{\mathrm{A}}$-receptor subtypes which rendered them benzodiazepine-insensitive [8]. Thereby, particular circuits became pharmacologically silent while their physiology remained fully functional. The corresponding pharmacological deficit in the mutant mouse lines revealed the function of the respective receptor in wild type mice. With this strategy the benzodiazepine-induced spectrum of behaviour was dissected genetically. The new knowledge of a circuit-specific brain pharmacology permitted the development of circuit-specific drugs by targeting selective $\mathrm{GABA}_{\mathrm{A}}$ receptor subtypes. The therapeutic indications for these agents are predictable and include sleep disorders, epilepsy, anxiety disorders, schizophrenia and memory impairment.

\section{A New Therapy for Anxiety Disorders}

Anxiety disorders come in different types such as generalized anxiety disorders, panic attacks or anxious depression. We had previously shown that a deficit of GABAergic inhibitory transmission can trigger excessive anxiety and a heightened response to threat cues [9]. Benzodiazepines are frequently prescribed as anxiolytic drugs although their use as tranquillizers is limited by sedative side effects. The development of anxiolytic drugs devoid of drowsiness was a goal which appeared to be elusive for the last thirty years. However, a neurobiological basis for the separation of sedation and anxiolysis was recently detected. Circuits expressing $\alpha 2 \mathrm{GABA}_{\mathrm{A}}$ receptor subtypes in the brain were found to selectively mediate tranquillising actions, while sedation was mediated by totally different circuits characterized by $\alpha 1 \mathrm{GABA}_{\mathrm{A}}$ receptors (Fig. 3) [10]. Thus, by developing $\alpha 2 \mathrm{GABA}_{\mathrm{A}^{-}}$-receptor-specific ligands a new pharmacology for anxiolytic drugs is on the horizon.

\section{Treating Memory Disorders}

Memory disorders and dementias such as Alzheimer disease are among the most severe brain disorders since they affect the core of human personality. The pharmacological improvement of memory processing

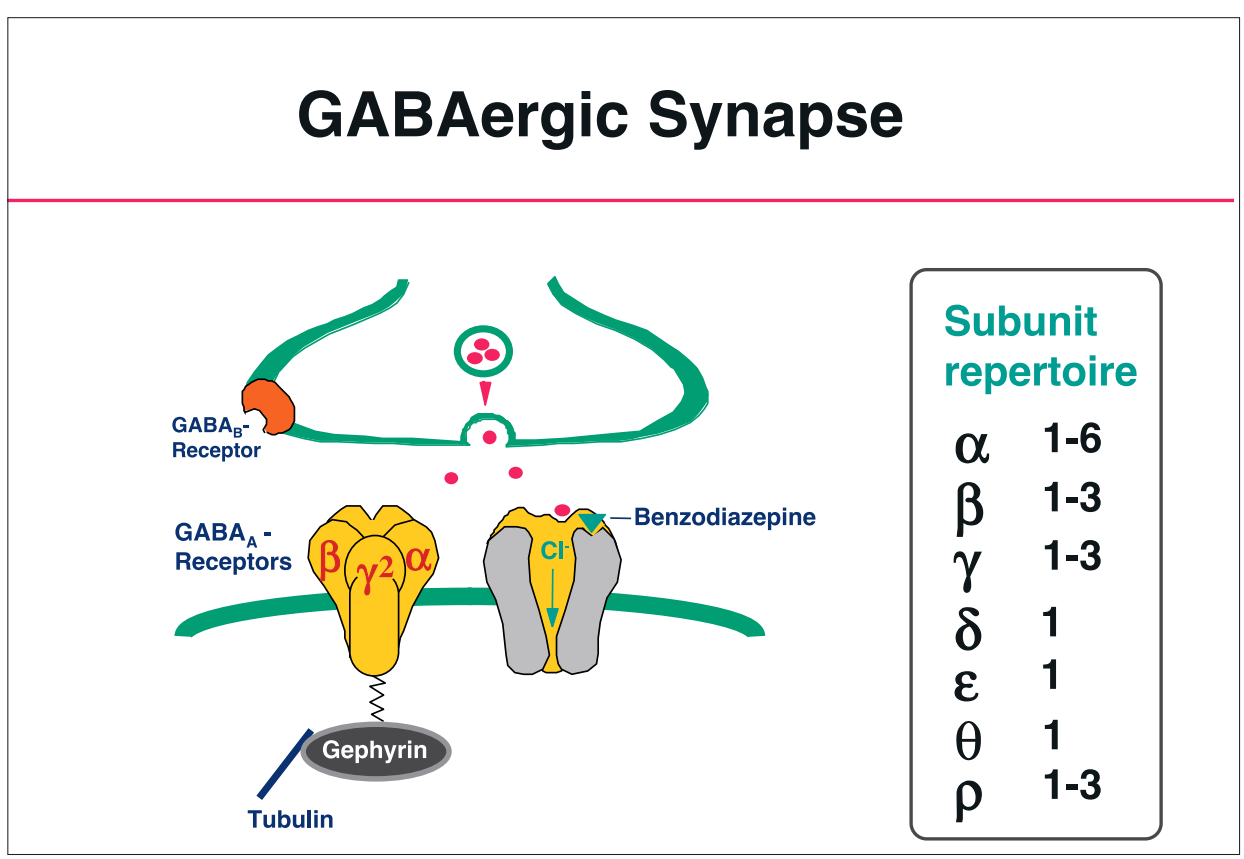

Fig. 2. Molecular architecture of GABAergic synapse with the subunit repertoire of GABAA receptor subtypes. has focused mainly on the cholinergic system (acetylcholinesterase inhibitors) and on the cyclic AMP dependent pathways (inhibition of phosphodiesterase 4 and enhancement of cAMP response element binding protein) and on the activation of excitatory transmission via NMDA receptors. So far, only acetylcholinesterase inhibitors and NMDA receptor ligands have shown some therapeutic benefit. It is therefore a major therapeutic aim to identify additional tar- gets in the regulation of cognitive processing. By generating a mouse line with a slight deficit of extrasynaptic GABAergic transmission in the hippocampus - a brain area critically involved in memory formation $-\alpha 5 \mathrm{GABA}_{\mathrm{A}}$ receptors were identified as novel regulators of memory processing [11]. Thus, memory processing in the hippocampus can not only be enhanced by strengthening excitatory transmission but also by dampening inhibitory neurotrans-

\section{GABA $_{A}$-receptor subtypes and behaviour}

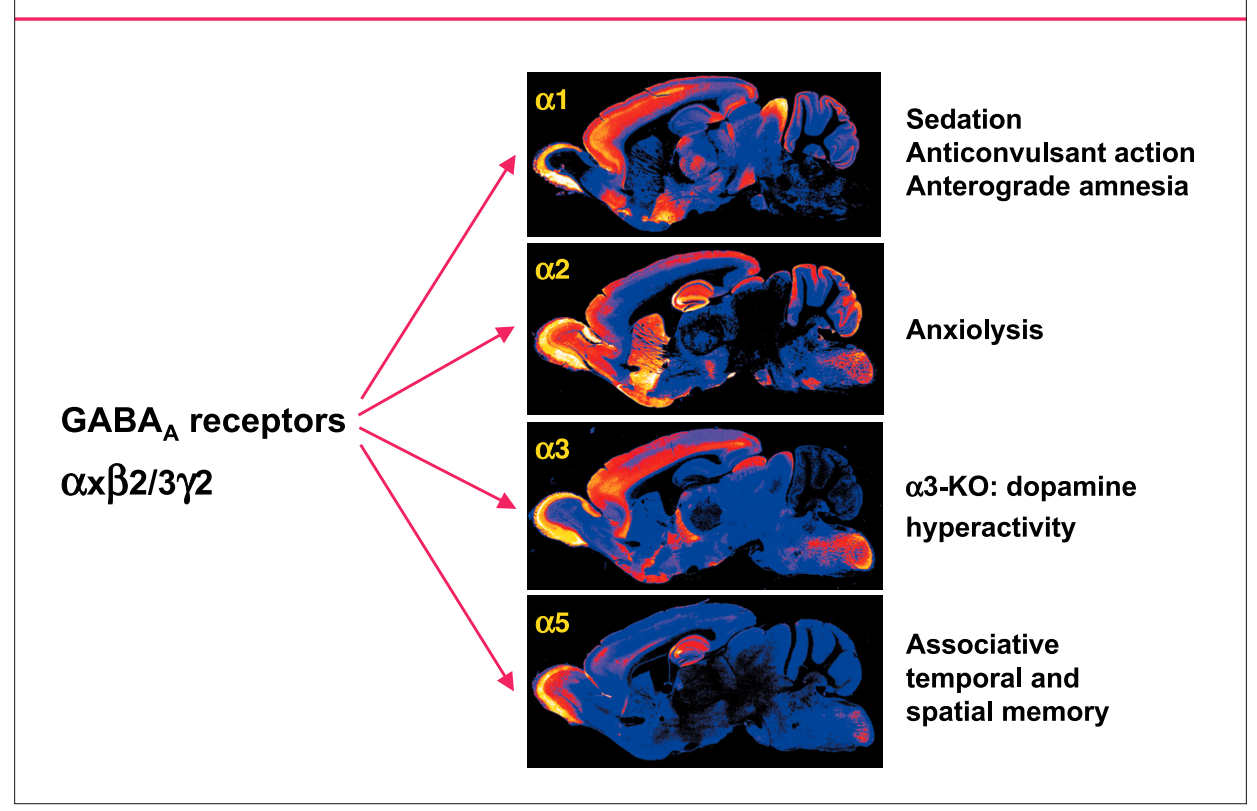

Fig. 3. GABAA receptor subtypes $(\alpha 1, \alpha 2, \alpha 3, \alpha 5)$ serve as tags for distinct GABA circuits in the brain. Their functional roles for drug development are indicated. The images represent the immunohistochemical distribution of the respective GABAA receptor subtype. 
mission. On the basis of this discovery, inverse agonists acting selectively on $\alpha 5 \mathrm{GABA}_{\mathrm{A}}$ receptors have been synthesized by Merck Sharp \& Dohme Research Laboratories and found to improve memory performance in animals [12]. Thus, a novel approach to enhance memory performance has been identified based on the selective dampening of neuronal inhibition in the hippocampus [13].

\section{A Pharmacology for Developmental Disorders?}

Various brain disorders such as Rett syndrome, schizophrenia, epilepsy or autism are thought to arise in later life due to abnormalities which occur during brain development [14]. It is therefore mandatory to understand the mechanisms controlling brain development. A hallmark of this process, termed neuronal plasticity, is the ability of the brain to adjust to environmental stimuli. The phenomenon of plasticity has been most intensively investigated in the development of the visual system [15]. Hard-wired circuits are laid down during early brain development. Subsequently, these circuits undergo a reality check driven by sensory experience which takes place in a particular critical period of development. In the visual system, selective inhibitory neurons in the primary visual cortex have been identified to play a major role in the critical period plasticity. They shape the dendritic arbour of incoming thalamic neurons carrying sensory information to the primary visual cortex. Specifically, neurons operating with $\alpha 1 \mathrm{GABA}_{\mathrm{A}}$ receptors were found to be critical determinants in the experience-driven adaptation of these connections [16]. Thus, the understanding of the cellular and molecular underpinnings of the regulation of normal brain development is an important first step in recognizing potential abnormalities. In the future, developmental biology may open a new field of research in which the pathologies of development are better understood. Brain disorders such as Rett syndrome, schizophrenia, epilepsy or autism may become amenable to a developmental pharmacology, a very challenging new field of research.

\section{Outlook}

To improve the treatment of brain disorders it will be necessary to continue to translate the advances in basic neuroscience into improvements of therapeutic strategies. Pharmacology is the melting pot to combine different disciplines such as human genetics, imaging, animal models, developmental and systems biology and medicinal chemistry, to develop new phenotypes and future therapeutics.

\section{Acknowledgements}

The contribution of former and present members of the laboratory is gratefully acknowledged in particular Jean-Marc Fritschy, Florence Crestani, Dietmar Benke, Bernhard Lüscher and Uwe Rudolph.

Received: August 3, 2004

[1] H. Möhler, T. Okada, Science 1977, 198, 849.

[2] H. Möhler, M.K. Battersby, J.G. Richards, Proc. Natl. Acad. Sci. USA 1980, 77, 1666.

[3] H. Möhler, in 'Pharmacology of GABA and Glycine Neurotransmission', Ed. H. Möhler, Springer Publisher, Berlin 2001, p.101.

[4] J.M. Fritschy, H. Möhler, J. Comp. Neurol. 1995, 359, 154.
[5] J.M. Fritschy, D. Benke, S. Mertens, W.H. Oertel, T. Bächi, H. Möhler, Proc. Natl. Acad. Sci. USA 1992, 89, 6726.

[6] H. Möhler, J.M. Fritschy, U. Rudolph, J. Pharmacol. Exp. Ther. 2002, 300, 2.

[7] J.M. Fritschy, I. Brünig, Pharmacol Therapeutics 2003, 98, 299.

[8] U. Rudolph, F. Crestani, D. Benke, I. Brünig, J.A. Benson, J.M. Fritschy, J.R. Martin, H. Blüthmann, H. Möhler, Nature 1999, 401, 796.

[9] F. Crestani, M. Lorez, K. Baer, Ch. Essrich, D. Benke, J.P. Laurent, C. Belzung, J.M. Fritschy, B. Lüscher, H. Möhler, Nature Neurosci. 1999, 2, 833.

[10] K. Löw, F. Crestani, R. Keist, D. Benke, I. Brünig, J.A. Benson, J.M. Fritschy, T. Rülicke, H. Bluethmann, H. Möhler, U. Rudolph, Science 2000, 290, 131.

[11] F. Crestani, R. Keist, J.M. Fritschy, D. Benke, K. Vogt, L. Prut, H. Blüthmann, H. Möhler, U. Rudolph, Proc. Nat. Acad. Sci. USA 2002, 99, 8980.

[12] M.S. Chambers, J.R. Atack, H.B. Broughton, N. Collinson, S. Cook, G.R. Dawson, S.C. Hobbs, G. Marshall, K.A. Maubach, G.V. Pillai, A.J. Reeve, A.M. MacLeod, J. Med. Chem. 2003, 46, 2227.

[13] J.M. Fritschy, F. Crestani, U. Rudolph, H. Möhler, in 'Excitatory-Inhibitory Balance, Synapses, Circuits, Systems', Ed. T. Hensch, M. Fagiolini, Plenum Publishers, New York 2004, p. 213.

[14] H.Y. Zoghbi, Science 2003, 302, 826.

[15] T.N. Wiesel, D.H. Hubel, J. Neurophysiol. 1963, 26, 1003.

[16] M. Fagiolini, J.M. Fritschy, K. Löw, H. Möhler, U. Rudolph, T.K. Hensch, Science 2004, 303, 1681. 